\title{
更 正
}

本刊收到“一氧化氮抑制恶性胸腔积液形成的机制”一文(发表于 2018, 48(7): 795-801; doi: 10.1360/N05 2018-00063)通信作者施焕中教授的署名更正请求，将姜帅、吴秀芝为共同第一作者变更为姜帅为第一作者. 此 更正得到全体作者姜帅、吴秀芝、翟㑆、伊风双、王臻、王政、叶志坚、杨卫兵、施焕中的一致同意和签名 认可. 作者对由此给期刊和读者造成的困扰深表歉意. 更改后的署名如下：

\section{一氧化氮抑制恶性胸腔积液形成的机制}

姜帅 ${ }^{1}$ ，吴秀芝 ${ }^{1}$ ，翟㑆 ${ }^{1}$ ，伊凤双 ${ }^{1}$ ，王臻 ${ }^{1}$ ，王政 ${ }^{1}$ ，叶志坚 ${ }^{2}$ ，杨卫兵 ${ }^{3}$ ，施焕中 ${ }^{*}$

1. 首都医科大学附属北京朝阳医院呼吸与危重症医学科, 北京 100020 ;

2. 中山大学附属佛山医院呼吸内科, 佛山 528000;

3. 华中科技大学同济医学院附属协和医院呼吸与危重症医学科, 武汉 430022

* 联系人, E-mail: shihuanzhong@ @ina.com

doi: 10.1360/SSV-2019-0150 